\title{
Comparative study of Y-split recession versus bilateral medial rectus recession for surgical management of infantile esotropia
}

This article was published in the following Dove Press journal:

Clinical Ophthalmology

23 May 2014

Number of times this article has been viewed

\author{
Nermeen Badawi \\ Khaled Hegazy \\ Ophthalmology Department, Faculty \\ of Medicine, Menoufiya University, \\ Shebin El-Kom, Menoufiya, Egypt
}

Aim: This prospective study compares the results of bilateral medial rectus recession versus (vs) Y-split recession of medial recti techniques for surgical management of essential infantile esotropia.

Patients and methods: Thirty patients were included in this study and had preoperative infantile esotropia with large angles (ie, $>30$ prism diopters [PD]). Patients were divided into Group A, which underwent bilateral medial rectus (BMR) recession and Group B, which underwent bilateral Y-split recession of medial recti muscles. All patients were subjected to complete ophthalmologic examination and met the criteria for inclusion in this study. The degrees of BMR recessions performed ranged from $6.0-7.5 \mathrm{~mm}$. All operations were performed under general anesthesia. Follow-up visits were conducted at 1 and 2 weeks, and 1, 3, and 6 months postoperatively. Rates of reoperation for residual esotropia and consecutive exotropia were determined. Results: The patients' preoperative angles of deviation ranged from 30-80 PD. Group A consumed 57\% less operative time than Group B. Immediately postoperatively, the Y-splitting technique showed satisfactory results (ie, orthotropic or residual angles $\leq 15$ PD) in $73 \%$ of patients vs $67 \%$ only for the BMR recession patients. By the end of six months of follow up; $13 \%$ of the BMR technique patients vs $27 \%$ of the Y-splitting technique patients showed negative change of PD but without reoperation.

Conclusion: Our results suggest that, although the Y-splitting technique is more difficult and time consuming, both procedures are effective and have shown comparable results for the correction of horizontal deviation $\leq 70 \mathrm{PD}$.

Keywords: BMR recession, Y-splitting technique, torque reduction, oculomotor pathology, strabismus, faden operation

\section{Introduction}

The management of essential infantile esotropia has changed over the years. The movement of the human eye can be regarded as the simple rotation of the eyeball in its socket. Therefore, the relevant entity to consider is not the force (F) exerted by each extraocular muscle on the eyeball, but rather the torque $(\mathrm{T})$ that is exerted by each muscle, with the lever arm (r):

$$
\mathrm{T}=\mathrm{F} * \mathrm{r}
$$

Some oculomotor pathology can be treated by reducing the extraocular muscle contraction $\mathrm{T}$ on the eyeball. Different modalities of management of this condition can achieve a reduction in $\mathrm{T}$ : one can either reduce $\mathrm{F}$ exerted by the muscle, or one can reduce $r$. F reduction can be achieved by a number of techniques; one of them
Correspondence: Nermeen Badawi Ophthalmology Department, Menoufiya University, 3 Ibn-Hanbal Street,

7th District, Nasr City, Cairo, Egypt I |47 I

Tel +2010 00853835

Email badawi.nermeen@yahoo.com 
is bilateral maximal recession of the affected medial rectus (MR) muscles. ${ }^{1-6}$ In the past, large recessions of the MR of more than $6 \mathrm{~mm}$ were avoided for fear of producing adduction deficits. However, the safety and efficacy of the 7-8 mm bilateral medial rectus (BMR) recession has since been proven, ${ }^{7-12}$ and some authors have proposed even larger recessions. ${ }^{8,9,13}$

Different surgical approaches have been proposed for the reduction of $r$. One of these approaches involves Y-splitting of the extraocular muscle into two halves and reattaching the two halves at an angle to each other, by which the effective $r$ of this muscle can be significantly reduced. ${ }^{14-18}$ This technique is referred to as Y-split recession. Y-split recession of the MR has recently been developed to weaken extraocular muscles. It avoids the inadequacies of the alternative technique that reduces the effective $r$, which is the recession known as Cüppers' Faden operation (a technique for the treatment of variable angle strabismus, also referred to as "posterior fixation" or "retro-equatorial myopexy"). With the Faden operation, the global and orbital layers of the rectus muscles are typically kept together, and both the muscle and the surrounding muscle sheets are sutured to the globe, leading to incomitance increase. ${ }^{14,15}$ In the $\mathrm{Y}$-split recession of MR technique, T reduction is caused by shortening of the effective $r$ of the muscle. The muscle is split along $15 \mathrm{~mm}$, and both ends are reattached separately, offering the advantage that the $r$ of the muscle (and thereby the rotating $\mathrm{T}$ ) is reduced, without any pull in the radial direction. ${ }^{17,18}$

\section{Patients and methods}

Thirty patients were included in this study who had preoperative congenital esotropia with a large angle $(>30$ prism diopters [PD]). Patients were divided into Group A, which underwent BMR recession and Group B, which underwent bilateral Y-split recession of the MR muscles. All patients were subjected to complete ophthalmologic examination and met the criteria for inclusion in this study, which were as follows: 1) esotropia documented by an ophthalmologist before the age of 6 months; 2) alternation of fixation; and 3) preoperative deviation angle $>30 \mathrm{PD}$ determined by using the Hirschberg test, cover test, and Krimsky prism test for near and distance vision. Patients were excluded if neurological abnormalities or developmental delays were documented and if structural eye abnormalities were present. Visual acuity was examined using a Snellen acuity chart for children older than 3 years. Cycloplegic refraction was performed to exclude the accommodative component. Ocular motility, duction, and version movements were examined. Vertical incompliance (V or A pattern), oblique muscle overaction, and dissociated strabismus were recorded. In accordance with the results of the preoperative examination, the size of BMR recessions performed ranged from 6.0 to $7.5 \mathrm{~mm}$. All operations were performed under general anesthesia.

Follow-up visits were conducted at 1 and 2 weeks; and 1,3 , and 6 months postoperatively. Krimsky prism test as well as eye movement were assessed during follow-up examinations. Rates of reoperation for residual esotropia, consecutive exotropia (XT), oblique muscle overaction, or dissociated vertical deviation were determined. All patients' legal representatives were informed of the possible side-effects of the surgical procedure before the operation and gave written consent, according to the Declaration of Helsinki.

The patients' ages at the time of surgery for Group A (BMR recession) ranged from $0.67-4.00$ years, with a mean of 2.09 years (standard deviation [SD], \pm 1.09 ), while for Group B (Y-split recession) ages ranged from $0.75-4.50$ years, with a mean of 2.16 years $(\mathrm{SD} \pm 1.15)$; the mean postoperative follow-up interval was 6 months for both groups.

Menoufiya University Hospitals regulations and ethics protocols concerning the use of human volunteers were followed during this research.

\section{Group A (BMR) surgical technique}

All patients underwent a BMR recession using a limbal incision. The recession was measured from the muscle insertion, and the muscle was sutured directly to the sclera. The intramuscular membrane and the check ligaments were lysed in the course of the procedure. The conjunctiva was not recessed.

\section{Group B (Y-split recession) surgical technique}

For the Y-split recession, both MR muscles were split at a length of $15 \mathrm{~mm}$, and the two parts were reinserted on the globe surface with two non-absorbable sutures. First, the muscle was carefully cut using blunt West cottscissors (Acme United Corporation, Fairfield, CT, USA) along a length of $15 \mathrm{~mm}$, avoiding damage to the nutritional vessels. To obtain the correct new insertion points for the two muscle halves, we employed the following procedure. A first orientation point, labeled (a), was located in the middle of the natural insertion of the muscle. A second point, labeled (b), was located $6 \mathrm{~mm}$ directly behind (a). With the compasses centered at (a), the distance we defined as $r_{a}$ was marked on the globe with methylene blue (Figure 1). The same procedure was repeated from point (b), with the distance $r_{b}$. The intersection point of 


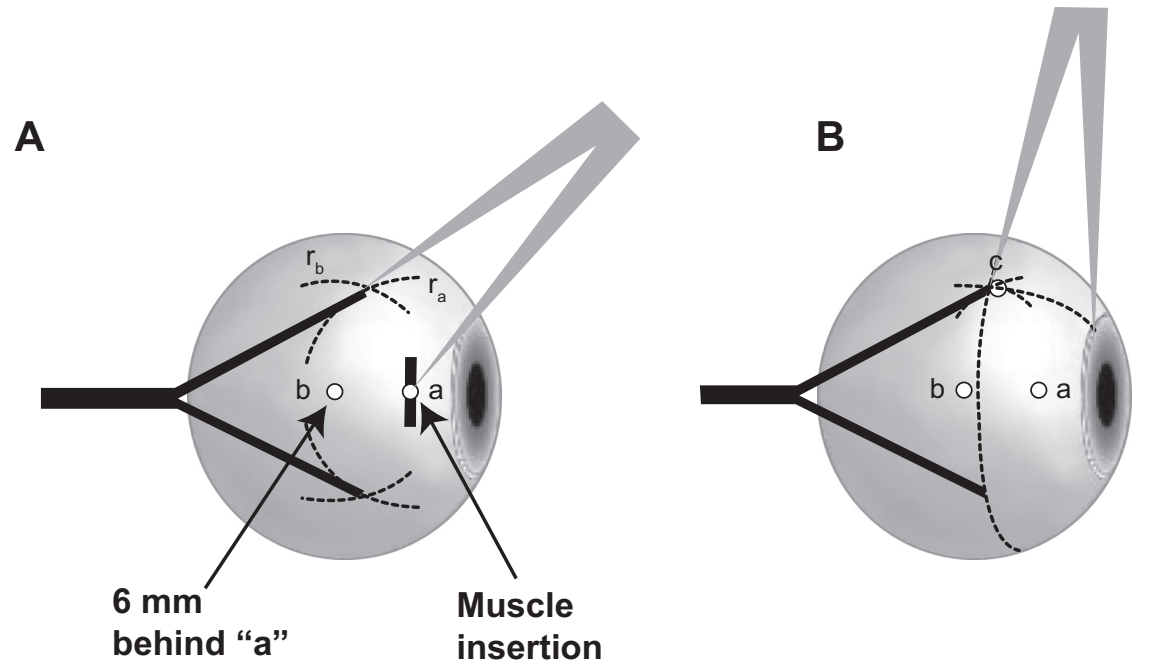

Figure I Y-split recession, side view.

Notes: (A) The first orientation point (a) is determined by the natural midpoint of the muscle insertion. The second orientation point (b) is located 6 mm directly behind a. With a compass, the distance $r_{a}$ is marked with colored dye on the globe. The same procedure is repeated from $b$, with the distance $r_{b}$ marked with colored dye as well. The intersections of the two marked lines indicate the new insertion points for the split muscle halves. (B) The control distance (c) ensures the correct placement of the new insertion points.

the two methylene blue lines (c) marked the new insertion point of the first muscle half.

At the end of the procedure, the angle between the two muscle parts was measured by a compass to ensure adequate splitting, and was found to be $62.8 \pm 5.7^{\circ}$. A detailed description of the surgical technique has been presented previously by Hoerantner et al. ${ }^{18}$ First, the muscle is hooked and isolated (Figure 2A), then a distance of $15 \mathrm{~mm}$ is measured from the insertion point (Figure $2 \mathrm{~B}$ ), and the muscle is split with scissors along the length of $15 \mathrm{~mm}$ (Figure 2C). The upper and lower muscle halves are sutured (Figure 2D and E), then disinserted. To obtain the correct new insertion points for the two muscle halves, we employed the procedure indicated in the side view in Figure 1; to ensure that the marks are placed correctly, we suggest measuring the minimum distance between the cornea limbus and the new insertion (control distance, as in Figure 2F). This provides a simple check if the two new insertions of the muscle parts are correct. Then, the two muscle halves can be sutured at the two new insertion points (Figure 2G and $\mathrm{H}$ ).

In patients on whom inferior oblique overaction was recorded preoperatively, myectomy of $8 \mathrm{~mm}$ of these muscles was performed during the same operation. This was performed on four cases in Group A and three cases in Group B.

\section{Results}

For both groups, the age distribution was similar for both techniques as shown in Figure 3. Patients' preoperative angle of deviation values for Group A (BMR recession) ranged from 30-80 PD, with a mean of 49.33 PD (SD \pm 13.07$)$, and for Group B (Y-split recession) it ranged from 40-80 PD, with a mean of 54.33 PD ( $\mathrm{SD} \pm 12.80)$. The mean postoperative follow-up interval was 6 months for both groups. The mean operative time for Group A (BMR recession) was 30 minutes ( $\mathrm{SD} \pm 1.00$ ), and for Group B (Y-split recession) it was 70 minutes ( $\mathrm{SD} \pm 13.50)$. This means that Group A utilized 57\% less operative time than Group B.

Immediately postoperatively, the BMR recession technique showed satisfactory results (ie, orthotropic or residual angle $\leq 10 \mathrm{PD}$ ) in $67 \%$ of patients versus (vs) $73 \%$ of patients in the Y-split group. The immediately postoperative unsatisfactory results were in the form of residual angle of deviation $>10$ PD that was encountered in $27 \%$ of BMR patients vs $13 \%$ of $\mathrm{Y}$-split patients. The other unsatisfactory postoperative result was consecutive XT that occurred in $6 \%$ of BMR patients vs $13 \%$ of Y-split patients (Figure 4). Cases with unsatisfactory results in the form of residual angle $>15$ PD were managed surgically in the form of re-recession (in the BMR group), or reuniting split halves of the MR and recession (for the $\mathrm{Y}$-split group), while the cases of XT were managed by advancement in the BMR group and bilateral rectus recession in the $\mathrm{Y}$-split group.

Comparing the immediate postoperative surgical outcomes with outcomes at 6-month follow-up (Figure 5), $13 \%$ of the BMR patients showed negative changes with no reoperation vs $27 \%$ in the $\mathrm{Y}$-split group. Concerning satisfaction with immediate results and postoperative changes, 

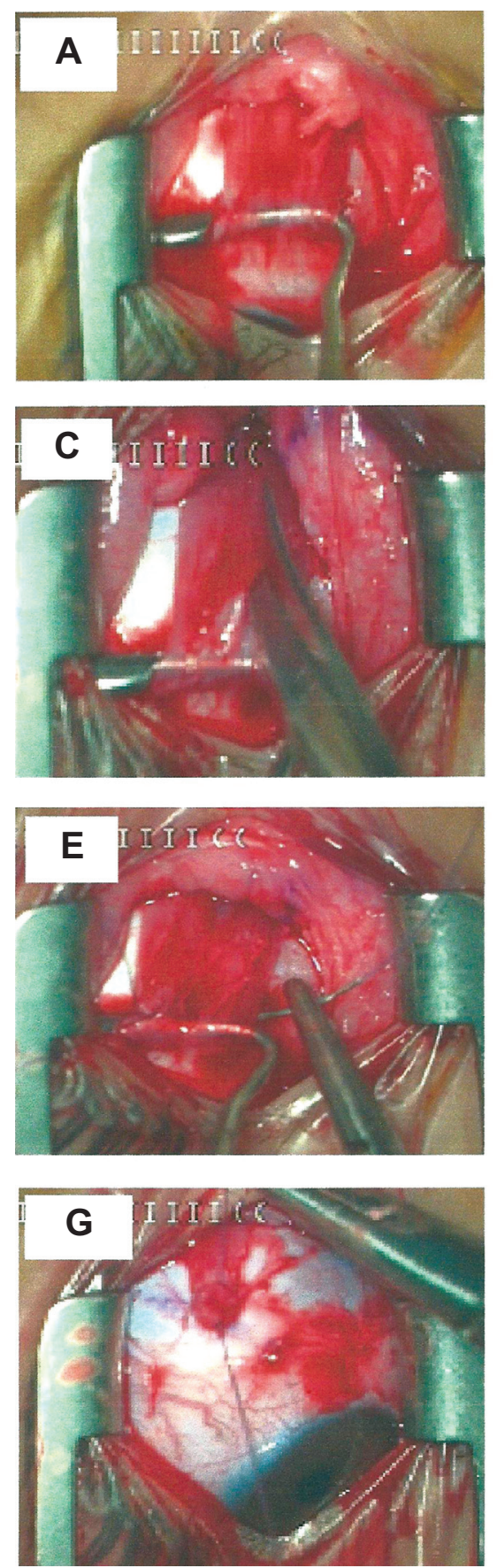
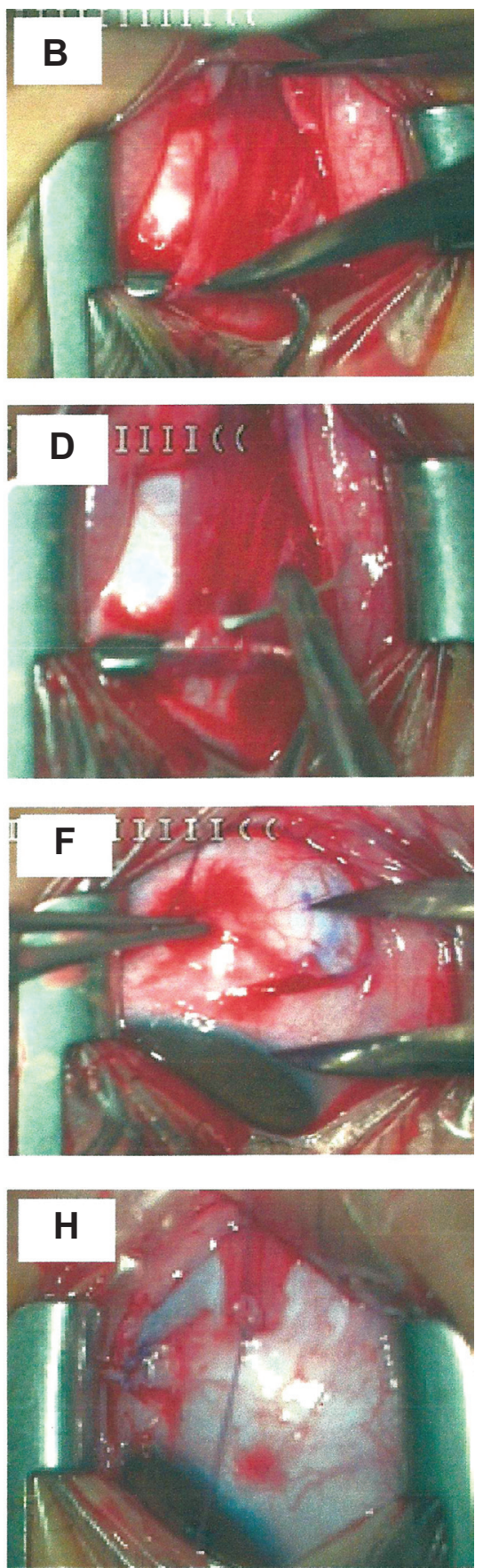

Figure 2 Steps in $Y$-split recession.

Notes: (A) The MR is hooked. (B) A $15 \mathrm{~mm}$ distance from the insertion is measured. (C) The muscle is split along the I5 mm. (D and E) The upper and lower MR halves are sutured. (F) The minimum distance from the limbus to the new insertion is measured. ( $\mathbf{G}$ and $\mathbf{H})$ The two muscle halves are sutured at the new insertion points. Abbreviation: MR, medial rectus.

two patients in the Y-split group showed satisfactory results immediately after the operation, but we observed negative changes within the next 6 months. Changes were for the worse, from esotropia with a PD of 10 to esotropia with a PD of 15 in one patient, and from orthophoria to esotropia with a PD of 20 in a second patient. Statistical analysis by $P$-value of the final output of both surgeries showed no statistical significance in the comparison of the efficacy of one technique over the other.

\section{Discussion}

In recent years, several authors have advocated that BMR recession in excess of the traditional $5 \mathrm{~mm}$ can be used for the correction of large angle infantile esotropia. Hess \& Calhoun ${ }^{7}$ 


\section{Patients' distribution by age}

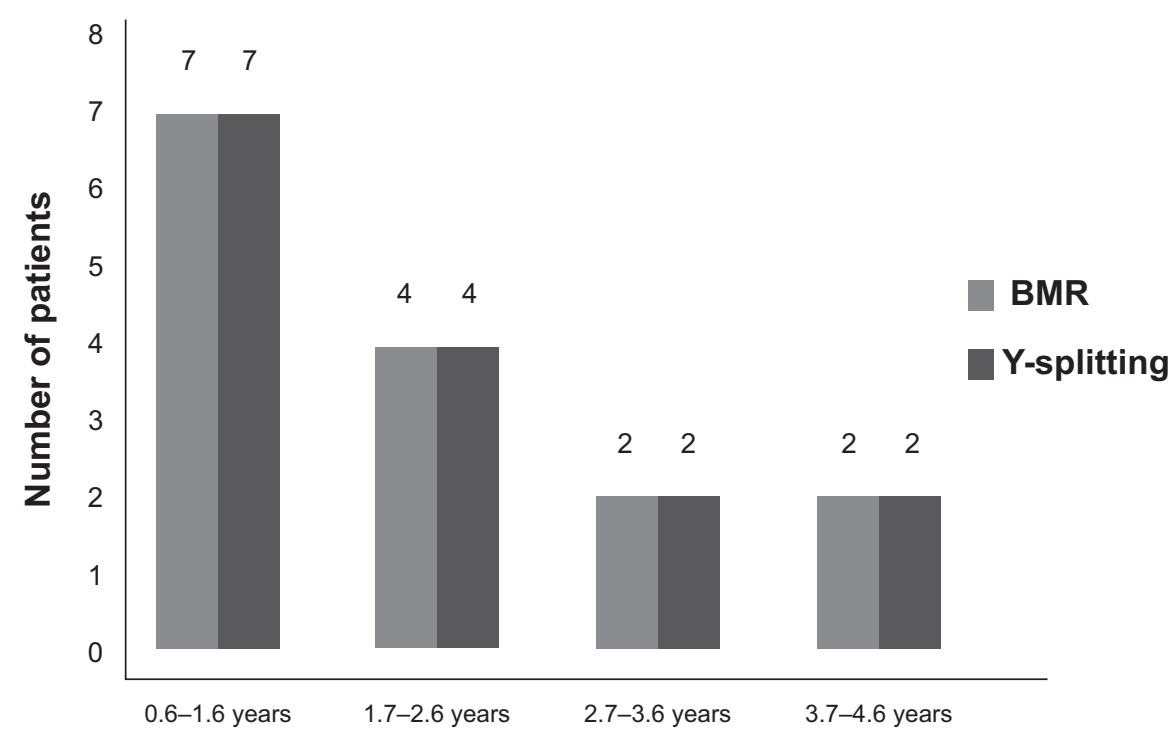

Figure 3 Patients' profiles showing patients' distribution by age. Abbreviation: BMR, bilateral medial rectus.

were early proponents for such a procedure, followed by Mittelman and Folk, ${ }^{19}$ Prieto-Diaz, ${ }^{8}$ and Szmyd et al. ${ }^{9}$ Later advocates included Nelson et al, ${ }^{10}$ Weakley et al, ${ }^{11}$ Biedner et al, ${ }^{20}$ and more recently Damanakis et al. ${ }^{21}$ These studies reported a success rate ranging between $75 \%-91 \%$ in early esotropia with bilateral limitation of abduction in performing
BMR recession from 6-8 $\mathrm{mm}$ over follow-up ranging from 6-24 months.

All the above authors ${ }^{7-11,19}$ observed that a large BMR recession, which exceeds the traditional maximum recession of the MR, does not produce clinically significant limitation of adduction or convergence. So, the fear of

\section{Satisfactory vs unsatisfactory results}

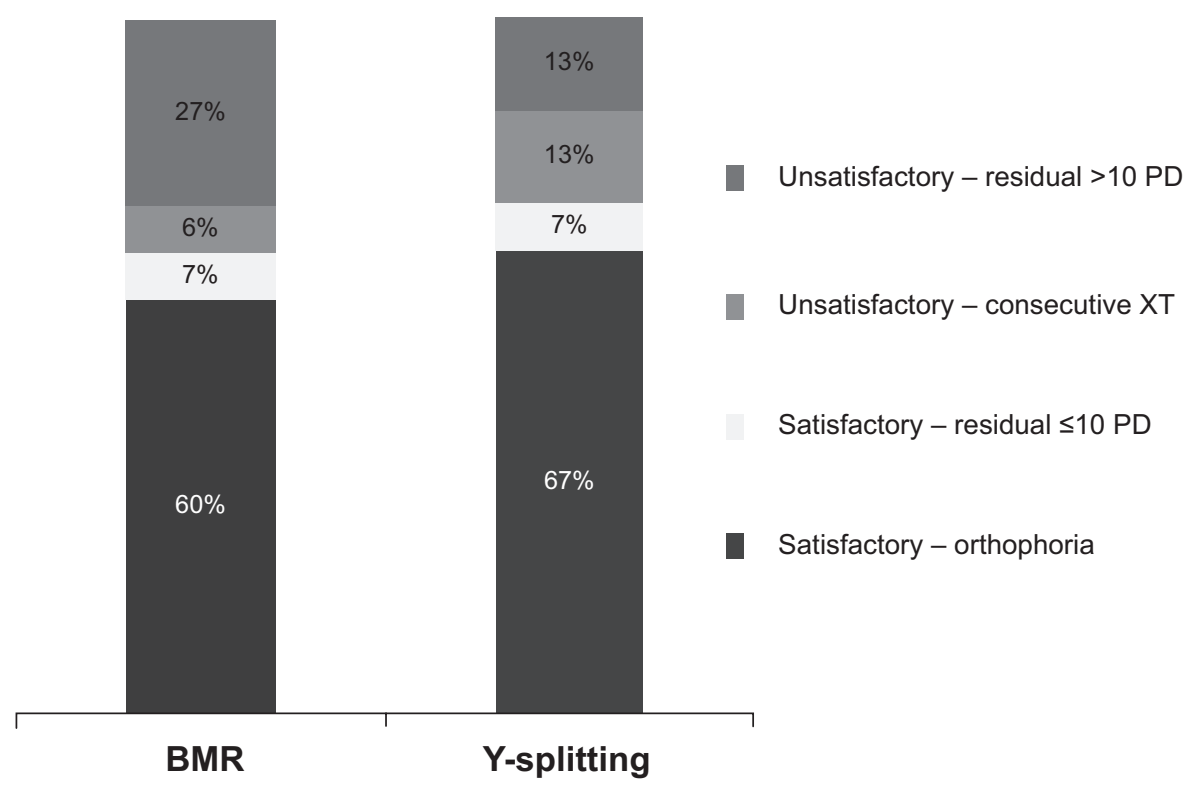

Figure 4 Immediate postoperative results.

Abbreviations: PD, prism diopters; $\mathrm{XT}$, exotropia; BMR, bilateral medial rectus; vs, versus. 


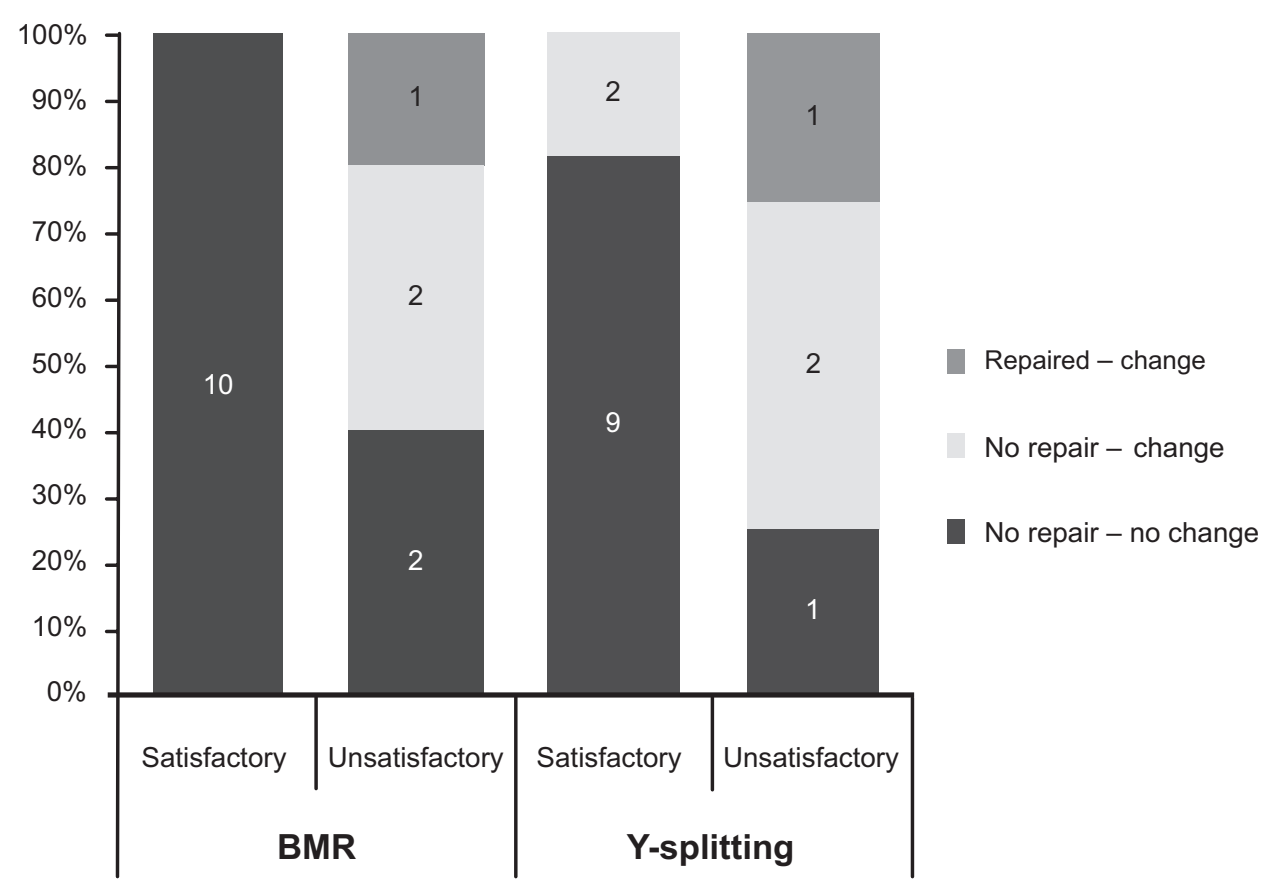

Figure 5 Postoperative results at 6 months' follow-up.

Abbreviation: BMR, bilateral medial rectus.

producing adduction or convergence deficits when such extra-large recessions are used is not justified. Our results also showed that such problems did not occur when very large recessions were performed for the correction of infantile esotropia.

This study showed that $34 \%$ of our patients needed further correction for strabismus patterns after correcting infantile esotropias by BMR recession with a range from $6.0-7.5 \mathrm{~mm}$ during the follow-up period of 6 months. As confirmed by many other studies, ${ }^{19-21}$ a retrograde study on long-term results of BMR recessions, done by Keskinbora and Pulur ${ }^{22}$ denoted that further correction for new strabismus patterns occurred in approximately $50 \%$ of their patients. These results are relatively comparable to this study's results.

Stager and Weakley ${ }^{23}$ reported a $20 \%$ incidence of delayed consecutive XT in their patients, who had undergone $7 \mathrm{~mm}$ BMR recessions, after an average of 23 months following initial surgery. They stated that the incidence of consecutive XT differed according to the age at which the initial operation was performed. Those operated on at 4-6 months of age had a larger incidence (33\%), while those operated on at or after 9 months of age had a lower incidence (14\%). These results are further supported by another study ${ }^{24}$ on a series of operated patients with older age at the time of surgery, ranging from 18-38 months (average 26.6 months). Our study recorded only $7 \%$ of patients with consecutive XT by 1 week postoperative time that became orthotropic by 6-month follow-up time (taking into consideration that the number of cases in this study is relatively small).

We believe that this single $\mathrm{Y}$-splitting procedure is quicker, simpler, and less traumatic than three or four muscle procedures in correction of high esotropias. In addition, the lateral rectus and oblique muscle are left intact for future surgeries if necessary.

In pathologies with variable strabismus angles, like infantile esotropia, the treatment of oculomotor T reduction by reducing $\mathrm{r}$ of the oculomotor muscles is well established and generally quite successful. The newly developed technique of weakening the MR by Y-split recession of the MR is more difficult than BMR, but simpler than the Faden operation (for variable angle infantile esotropia). ${ }^{25}$

A modified Y-split recession technique was reported by Gupta et $\mathrm{al}^{24}$ as being successful in $80 \%$ of cases of infantile esotropia without postoperative complications during a mean follow-up period of 4.4 months. The authors concluded that modified Y-split recession is a safe and reasonably effective technique for infantile esotropia. This study showed that the modified technique was difficult and cumbersome, however. It required wider exposure of conjunctiva and Tenon's capsules. The MR had to be dissected $>15 \mathrm{~mm}$ in the orbit. However, when a second reoperation was needed, the split muscle was in place with no scar tissue to affect the reoperation; results that are supported by the work of Hoerantner et $\mathrm{al}^{25}$ who reported that only $1 \%$ of all patients 
who have undergone $\mathrm{Y}$-split recession have been reoperated on a few months later. In their study, the split muscle was found with no scar tissue between globe and muscle, and the muscle was situated as it was immediately after Y-split surgery. The wound surface of the split muscle was covered by smooth, white tissue unconnected to any other structure. They recorded that, 3 months after the operation, Y-split recession cases showed a significantly greater reduction in maximum strabismus angle.

\section{Conclusion}

The Y-splitting technique is much more difficult, time consuming and needs more experienced surgical skills than $\mathrm{BMR}$ recession. Our postoperative results suggest that both $\mathrm{Y}$-splitting and BMR recession procedures are effective, and have shown comparable outcomes for the correction of the horizontal deviation when it measures $\leq 70$ PD. Statistically, the final results of both surgeries showed no significance in the comparison of the efficacy of one technique vs the other. However, further evaluation involving a bigger number of cases is recommended.

\section{Disclosure}

The authors report no conflicts of interest in this work.

\section{References}

1. Leitch RJ, Burke JP, Strachan IM. Convergence excess esotropia treated surgically with faden operation and medical rectus muscle recessions. Br J Ophthalmol. 1990;74(5):278-279.

2. Stager DR, Weakley DR Jr, Everett M, Birch EE. Delayed consecutive exotropia following 7-millimeter bilateral medial rectus recession for congenital esotropia. J Pediatr Ophthalmol Strabismus. 1994;31(3): $147-150$.

3. Birch EE, Felius J, Stager DR Sr, Weakley DR Jr, Bosworth RG. Preoperative stability of infantile esotropia and post-operative outcome. Am J Ophthalmol. 2004;138(6):1003-1009.

4. Ruiz MF, Alvarez MT, Sánchez-Garrido CM, Hernáez JM, Rodríguez JM. Surgery and botulinum toxin in congenital esotropia. Can J Ophthalmol. 2004;39(6):639-649.

5. Elliott S, Shafiq A. Interventions for infantile esotropia. Cochrane Database Syst Rev. 2005;25(1):CD004917.

6. Hemmerdinger C, Rowe N, Baker L, Lloyd IC. Bimedial hang-back recession - outcomes and surgical response. Eye (Lond). 2005;19(11): 1178-1181.

7. Hess JB, Calhoun JH. A new rationale for the management of large angle esotropia. J Pediatr Ophthalmol Strabismus. 1979;16(6):345-348.

Clinical Ophthalmology

\section{Publish your work in this journal}

Clinical Ophthalmology is an international, peer-reviewed journal covering all subspecialties within ophthalmology. Key topics include: Optometry; Visual science; Pharmacology and drug therapy in eye diseases; Basic Sciences; Primary and Secondary eye care; Patient Safety and Quality of Care Improvements. This journal is indexed on
8. Prieto-Diaz J. Large bilateral medial rectus recessions in early esotropia with bilateral limitation of abduction. J Pediatr Ophthalmol Strabismus. 1980;17:101-105

9. Szmyd SM, Nelson LB, Calhoun JH, Spratt C. Large bimedial rectus recessions in congenital esotropia. Br J Ophthalmol. 1985;69(4): 271-274.

10. Nelson LB, Calhoun JH, Simon JW, Wilson T, Harley RD. Surgical management of large angle congenital esotropia. Br J Ophthalmol. 1987;71(5):380-383.

11. Weakley DR Jr, Stager DR, Everett ME. Seven-millimeter bilateral medial rectus recessions in infantile esotropia. J Pediatr Ophthalmol Strabismus. 1991;28(2):113-115.

12. Spiritus M. Large bimedial rectus recessions versus bimedial posterior fixation with additional rectus recessions. Trans 19th meeting ESA. Crete, June 1991:59-64. From: Alexandros GD, Panagos GA, Ioannis DL, George PT. $8 \mathrm{~mm}$ Bimedial rectus recession in infantile esotropia of 80-90 prism diopters. Br J Ophthalmol. 1994;78:842-844.

13. von Noorden GK. A reassessment of infantile esotropia. XLIV Edward Jackson memorial lecture. Am J Ophthalmol. 1988;105(1):1-10.

14. Castanera AM. Length-tension diagrams of medial rectus muscles after Cüppers' faden operation. Surgical assessment of the reversibility of posterior fixation sutures. Ophthalmologica. 1989;198(1): 46-52.

15. Roggenkämper P. The Faden operation. Technical aspects and indications. Bull Soc Belge Ophtalmol. 1989;232:25-31.

16. Priglinger S, Hametner H. Operative Methoden zur Behandlung des schwankenden Schielwinkels Mathematische Zusammenha "nge Computergestu" tzte Operatioin splanung. Spektrum Augenheilkd. 1994;8:162-175. German.

17. Haslwanter T, Hoerantner R, Priglinger S. Reduction of ocular muscle power by splitting of the rectus muscle I: biomechanics. $\mathrm{Br} J$ Ophthalmol. 2004;88(11):1403-1408.

18. Hoerantner R, Priglinger S, Haslwanter T. Reduction of ocular muscle torque by splitting of the rectus muscle II: technique and results. $\mathrm{Br} J$ Ophthalmol. 2004;88(11):1409-1413.

19. Mittelman D, Folk ER. The surgical treatment of under corrected esotropia: an evaluation of the effect of recession of the medial rectus muscle $13.5 \mathrm{~mm}$ from the limbus. Trans Sect Ophthamol Am Acad Ophthamol Otalaryngol. 1975;79(5):783-844.

20. Biedner B, Yassur Y, David R. Medial rectus re-recession in undercorrected esotropia. J Pediatr Ophthalmol Strabismus. 1992;29(2):89-91.

21. Damanakis AG, Arvanitis PG, Ladas ID, Theodossiadis GP. 8 mm bimedial rectus recession in infantile esotropia of 80-90 prism dioptres. Br J Ophthalmol. 1994;78(11):842-844.

22. Keskinbora KH, Pulur NK. Long-term results of bilateral medial rectus recession for congenital esotropia. J Pediatr Ophthalmol Strabismus. 2004;41(6):351-355.

23. Stager DR, Weakley DR Jr. Delayed consecutive exotropia following $7 \mathrm{~mm}$ bilateral medial rectus recession for infantile esotropia. AAPOS Meeting. April 1993:18-22. Palm Springs, CA, USA.

24. Gupta VP, Suraj Munjal, Das GK. Modified "Y-split recession" of medial recti for correction of infantile esotropia - a new modification. AIOC 2008 Proceedings.

25. Hoerantner R, Priglinger S, Koch M, Haslwanter T. A comparison of two different techniques for oculomotor torque reduction. Acta Ophthalmol Scand. 2007;85(7):734-738.
PubMed Central and CAS, and is the official journal of The Society of Clinical Ophthalmology (SCO). The manuscript management system is completely online and includes a very quick and fair peer-review system, which is all easy to use. Visit http://www.dovepress.com/ testimonials.php to read real quotes from published authors. 